\title{
Ensino Médio Integrado à Educação Profissional e Tecnológica: a relação entre o currículo integrado e a prática pedagógica docente
}

\author{
Secondary Education Integrated to Professional and Technological \\ Education: the relationship between integrated curriculum and \\ pedagogical practice of professors
}

Recebido: 27/08/0020 | Revisado: 12/01/2021 | Aceito: 14/01/2021 |

Publicado: 19/01/2021

Angeline Santos Castro

ORCID: https://orcid.org/0000-0001-87658291

Instituto Federal de Educação Ciência e

Tecnologia de Alagoas

E-mail: angeline.castro@ifal.edu.br

José Henrique Duarte Neto

ORCID: https://orcid.org/0000-0001-74417472

Instituto Federal de Educação Ciência e

Tecnologia de Pernambuco

E-mail: https://orcid.org/0000-0001-7441-

7472

Como citar: CASTRO, A.S.; DUARTE NETO, J.H.; Ensino Médio Integrado à Educação Profissional e Tecnológica: a relação entre o currículo integrado e a prática pedagógica docente. Revista Brasileira da Educação Profissional e Tecnológica, [S.I.], v. 1, n. 20, p. e11088, jan. 2021. ISSN 2447-1801. Disponível em: <http://www2.ifrn.edu.br/ojs/index.php/RBE $\mathrm{PT} /$ issue/view/192>.

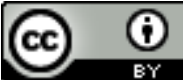

This work is licensed under a Creative Commons Attribution 4.0 Unported License.

\begin{abstract}
Resumo
O presente artigo tem a finalidade de analisar o currículo no que concerne à construção de uma prática pedagógica estruturada numa concepção de educação omnilateral, que aponte para o horizonte da emancipação humana. Os principais autores escolhidos para mediar esta discussão foram: Ramos (2012 e 2014), Ciavatta (2012, 2014), Gramsci (1982), Saviani (2011), Duarte Neto (2013) e Sacristán (1998). A coleta de informações realizou-se a partir da pesquisa bibliográfica e documental, de entrevistas semiestruturadas e de grupo focal. Para a análise das informações, tomamos como base a análise de conteúdo temática. Os achados da pesquisa evidenciam que a prática pedagógica no ensino médio integrado em que acreditamos, fundamentada numa formação politécnica e omnilateral, ainda está no horizonte.
\end{abstract}

Palavras-chave: Ensino Médio Integrado. Currículo Integrado. Prática Pedagógica. Formação Humana.

\begin{abstract}
His article had as purpose to analyze the curriculum concerning the development of a pedagogical practice based on a conception of omnilateral education that leads to human emancipation. The main authors chosen to mediate this discussion were: Ramos (2012, 2014 e 2017), Ciavatta (2012, 2014), Gramsci (1982), Saviani (2011), Duarte Neto (2013) e Sacristán (1998). The collect information it took place based of bibliographic and documentary research, as well as semi-structured interviews and focus group. The research findings evidenced that the pedagogical practice in the integrated secondary education we believe in, based on an omnilateral formation, is still on the horizon.
\end{abstract}

Keywords: Integrated Secondary Education. Integrated Curriculum. Pedagogical Practice. Human development. 


\section{INTRODUÇÃO}

A educação profissional surgiu no Brasil no período colonial marcada por uma perspectiva assistencialista, que tinha por objetivo inicial atender os "marginalizados da sociedade", e, em seguida no início do século XX, acatar as demandadas do mercado de trabalho. Ao longo desse movimento histórico, que promoveu e promove a dualidade estrutural, separando a formação geral da formação profissional, a educação profissional foi desenvolvida com a finalidade de atender ao mercado, não considerando a formação emancipatória dos sujeitos (MOURA, 2007). Nessa conjuntura, o ensino médio, última etapa da educação básica, passou por diversas descontinuidades na história da educação brasileira. De modo majoritário, promovendo a dualidade estrutural, ofertando a formação geral para a elite, que teria acesso ao ensino superior, e a formação profissional para os mais pobres. Em vista disso, atendendo a necessidade de mão de obra do mercado de trabalho.

Nesse sentido, o ensino médio sistematizado na última LDB (Lei № 9.394/96) aponta como uma das finalidades a preparação para o trabalho. O texto da Lei faz referência a uma perspectiva de acomodação nas ocupações, ou seja, de adaptação ao mercado do trabalho e não a uma compreensão do trabalho como essência humana. Estabelecendo uma relação direta entre educação e trabalho, como propõem o ensino médio integrado (EMI).

Em 2012 tivemos um pequeno avanço na educação profissional, que foi a normatização da Educação Profissional e Tecnológica de Nível Médio. Após um longo período de discussões, foram aprovadas as Diretrizes Curriculares Nacionais para a Educação Profissional Técnica de Nível Médio por meio do Parecer CNE/CEB № 11/12, de maio de 2012. Entendemos que as diretrizes apontam para construção de um currículo integrado. Contudo, são os sujeitos envolvidos no processo de ensino e aprendizagem e as condições materiais que concretizarão ou não a integração.

Desse modo, entendemos o ensino médio integrado como uma concepção pedagógica, que demanda uma formação ampla a partir dos fundamentos do trabalho, da ciência, da cultura e da tecnologia, visando à formação humana. É necessária a busca constante de se construir um EMI, que supere a dualidade entre formação geral e formação profissional e que tenha como objetivo a formação humana, de acordo com as necessidades dos jovens e adultos oriundos da classe trabalhadora (CIAVATTA; RAMOS, 2011).

Para melhor compreendermos a concepção de ensino médio integrado, também, evidenciaremos o estudo sobre o currículo, destacando a sistematização do currículo integrado. O currículo tem a função na práxis educativa de selecionar, organizar e socializar os conhecimentos historicamente elaborados em consonância com as finalidades da educação. O currículo integrado sistematiza os conhecimentos e estrutura o processo de ensino e aprendizagem de maneira que os conceitos sejam compreendidos em sua totalidade (RAMOS, 2012).

Nessa conjuntura, este estudo tem como objetivo geral analisar as práticas curriculares do Curso Técnico Integrado em Agropecuária do Instituto Federal de Educação, Ciência e Tecnologia de Alagoas - Campus Santana do Ipanema, a fim de levantar subsídios que contribuam para o fortalecimento de práticas pedagógicas orientadas ao ensino médio integrado. 
Para o alcance do referido objetivo fizemos a opção pelo método dialético e a pesquisa qualitativa. O campo de pesquisa escolhido foi o do Curso Técnico em Agropecuária do Instituto Federal de Educação, Ciência e Tecnologia de Alagoas (Ifal) - Campus Santana do Ipanema. O trabalho de campo permitiu-nos a aproximação com o universo empírico do objeto de estudo. Os participantes da pesquisa foram os docentes (licenciados e bacharéis) do referido curso. A coleta de informações com os sujeitos da pesquisa foi realizada por meio de dois procedimentos: a entrevista semiestruturada e o grupo focal. Para a análise das informações tomamos como base a análise de conteúdo temática.

Para mediar as discussões os principais autores escolhidos foram: Ramos (2012, 2014 e 2017), Ciavatta (2012, 2014), Gramsci (1982), Saviani (2011), Duarte Neto (2013), Sacristán (1998), dentre outros.

Para melhor localizar o leitor, estruturamos o artigo nas seguintes sessões: Concepção de ensino médio integrado à educação profissional; Currículo: concepções teóricas; Percurso metodológico da pesquisa; A prática pedagógica dos docentes do curso técnico integrado em agropecuária - análise e discussão dos resultados; e, por fim, estão as considerações finais.

\section{CONCEPÇÃO DE ENSINO MÉDIO INTEGRADO À EDUCAÇÃO PROFISSIONAL}

O ensino médio integrado propõe a articulação entre a formação geral (ensino propedêutico) e a formação profissional. Assim, provendo a relação entre a teoria e a prática, a problematização do trabalho como princípio educativo, a integração entre os vários componentes curriculares, a pesquisa como princípio pedagógico e a indissociabilidade entre o ensino, a pesquisa e a extensão. Nessa perspectiva, discutiremos a concepção de EMI na educação profissional e tecnológica (EPT).

A educação profissional e tecnológica de nível médio orienta a organização de seus currículos numa perspectiva que proporcione aos estudantes o "[...] diálogo com diversos campos do trabalho, da ciência, da tecnologia e da cultura como referências fundamentais de sua formação" (BRASIL, 2012). Assim, temos a sistematização do EMI com base no trabalho, na ciência, na tecnologia e na cultura visando à formação integral dos estudantes.

Dessa maneira, o EMI integra em seu currículo essas quatro dimensões, de forma que elas sejam indissociáveis e contemplem a formação humana dos sujeitos. Concebemos, também, que o EMI tem inspiração nas concepções de formação unitária, politécnica e omnilateral. Discutiremos adiante sobre essas concepções.

\subsection{FORMAÇÃO UNITÁRIA}

A escola única ou unitária proposta por Gramsci (1982) se organiza a partir da cultura geral, humanista e formativa. Promovendo o desenvolvimento do trabalho técnico e intelectual, sobretudo reforçando a capacidade autônoma e intelectual dos indivíduos. A escola unitária ou de formação humanista ou de cultura geral tem como 
objetivo introduzir os jovens na prática social, fomentando a maturidade intelectual e a autonomia nos estudos.

A escola unitária equivale ao que era considerado como escolas primárias e médias - o que hoje consideramos como educação básica. Para Gramsci (1982), no primeiro momento, os estudantes aprenderiam a: ler; escrever; fazer contas; estudar geografia e história; e ter noções sobre o Estado e a convivência em sociedade. No segundo momento, a escola instigaria a autonomia e a maturidade intelectual, com forte base humanística preparando os estudantes para a especialização posterior, nas universidades e/ou no mundo trabalho, "[...]esta fase escolar já deve contribuir para desenvolver o elemento da responsabilidade autônoma nos indivíduos, deve ser uma escola criadora" (GRAMSCI, 1982, p. 124).

Enquanto escola criadora pressupõe um procedimento de investigação e de conhecimento, orienta que as aprendizagens dar-se-ão a partir do trabalho autônomo do estudante, em que o professor atuará orientando esse percurso. Ela requer mudanças nos conteúdos e nos métodos de ensino (GRAMSCI, 1982).

Já a formação integrada se reconhece como um projeto de educação com inspiração na escola unitária de Gramsci, mas diferencia-se em virtude dos limites postos pela sociedade contemporânea, ou seja, pelas questões econômicas impostas pelo capital (ARAÚGO; FRIGOTTO, 2015).

\title{
2.2 FORMAÇÃO OMNILATERAL
}

A formação omnilateral é uma concepção filosófica que prevê a formação do ser humano integralmente nas dimensões física, mental, cultural, política, científica e tecnológica:

\begin{abstract}
Omnilateral é um termo que vem do latim e cuja tradução literal significa "todos os lados ou dimensões". Educação omnilateral significa, assim, a concepção de educação ou de formação humana que busca levar em conta todas as dimensões que constituem a especificidade do ser humano e as condições objetivas e subjetivas reais para seu pleno desenvolvimento histórico. Essas dimensões envolvem sua vida corpórea material e seu desenvolvimento intelectual, cultural, educacional, psicossocial, afetivo, estético e lúdico. Em síntese, educação omnilateral abrange a educação e a emancipação de todos os sentidos humanos (FRIGOTTO, 2012, p. 267).
\end{abstract}

De tal modo, a escola terá um novo papel na formação dos sujeitos, buscando as bases científicas e as relações culturais e sociais, tendo no horizonte uma sociedade igualitária. Os estudantes precisam ter acesso aos conhecimentos mais elevados que foram elaborados pela humanidade.

Essa concepção pressupõe o rompimento da fragmentação proposta pela base capitalista e parte "[...] dos sujeitos concretos, com sua cultura, saberes e senso comum, e dialogando criticamente com o patrimônio de conhecimentos existente - as 
bases científicas que permitem compreender como se produzem os fenômenos da natureza e as relações sociais (FRIGOTTO, 2012, p. 272). Talvez pensar essa educação seja um tanto utópico, mas é necessário buscar a superação social.

\subsection{FORMAÇÃO POLITÉCNICA}

Entendemos que a educação pode possibilitar aos indivíduos a apropriação dos conhecimentos mais elaborados construídos historicamente pela humanidade (SAVIANI, 2011). A formação politécnica não é entendida no sentido do ensino das muitas técnicas, mas no domínio dos fundamentos históricos, científicos e tecnológicos, proporcionando aos estudantes a possibilidade de escolha de sua trajetória.

Politecnia significa, aqui, especialização como domínio dos fundamentos científicos das diferentes técnicas utilizadas na produção moderna. Nessa perspectiva, a educação de nível médio tratará de concentrar-se nas modalidades fundamentais que dão base à multiplicidade de processos e técnicas de produção existentes (SAVIANI, 2007, p. 160).

Dessa maneira, não podemos traduzir formação politécnica como profissionalização, mas sim como um modo de organização do ensino médio que promova aos estudantes o acesso aos fundamentos das diversas técnicas empregadas na produção, ou melhor, que possibilite a compreensão das bases científicas que orientam o processo produtivo (SAVIANI, 2007).

Assim, compreendemos que, para se efetivar a relação entre educação e trabalho no ensino médio, é necessária a prática de uma concepção de educação inspirada na educação politécnica, omnilateral e na escola unitária. Rompendo a dualidade estrutural entre formação geral e formação profissional e entre uma educação diferenciada para a elite e para a classe trabalhadora. Destarte, "[...] politecnia, educação omnilateral, formação integrada são horizontes do pensamento que queremos que se transformem em ações" (CIAVATTA, 2014, p. 189).

Em vista disso, buscamos a elaboração do EMI inspirados numa educação politécnica e omnilateral. Desse forma, ele será planejado de modo que a formação geral se torne indissociável da formação profissional, centrado na formação humana e garantindo aos jovens e adultos "[...] o direito a uma formação completa pra a leitura do mundo e para atuação como cidadão pertencente a um país, integrado dignamente à sua sociedade política" (CIAVATTA, 2012, p. 85). A formação integrada, nessa compreensão, é contrária à formação para atender às demandas do mercado de trabalho, mas implica a incorporação dos conhecimentos historicamente construídos que caracterizam a vida humana.

Ramos (2017) propõe a "análise do conceito de integração" em três sentidos: concepção de educação omnilateral; indissociabilidade entre educação profissional e educação básica; e integração de conhecimentos gerais e específicos como totalidade na proposta curricular. Mais adiante, detalharemos os dois últimos sentidos, pois discorremos, anteriormente, sobre educação omnilateral. 
No segundo sentido, a indissociabilidade entre educação profissional e educação básica, a formação geral e profissional precisam andar juntas, em um projeto pedagógico único que permita que os estudantes se apropriem dos conhecimentos produzidos historicamente. Deste modo, assegurando a esses jovens e adultos escolhas conscientes, tanto para prosseguimento dos estudos em nível superior, quanto para uma possível atuação no mundo do trabalho.

A integração de conhecimentos gerais e específicos como totalidade na proposta curricular, nesse terceiro sentido, é compreendida para além de ter os componentes curriculares da formação básica e profissional compondo o mesmo currículo, haja vista que essa integração visa perceber a importância destes conteúdos na construção dos processos práticos e formativos dos estudantes. Desta forma, orienta-se deixar de lado o conceito positivista de currículo, que desarticula e compartimenta as ciências.

Além de pensar o EMI como uma oferta de ensino médio articulada com a formação profissional, busca-se compreendê-lo como formação humana integrada. Sendo assim, objetivamos que "[...] a superação da dualidade de classes sociais traga um padrão digno de vida e de conhecimento não apenas para as elites, mas também para os trabalhadores, os verdadeiros produtores da riqueza social, e seus filhos" (CIAVATTA, 2014, p. 202), bem como objetiva-se uma sociedade igualitária.

Na próxima seção, discorreremos sobre as concepções teóricas de currículo, discutindo o currículo integrado.

\section{CURRÍCULO: CONCEPÇÕES TEÓRICAS}

A etimologia do "[...] termo currículo tem sua gênese no lexema scurrere, que, em latim, significa uma pista de corrida circular de atletismo, sendo, também, compreendido como uma pista de corrida de carros; podendo ainda significar caminho, jornada, trajetória, percurso e carreira" (DUARTE NETO, 2013, p. 56). Fazendo uma análise entre a origem da palavra e seu sentido na educação, podemos compreender que corrobora com a ideia de percurso.

A história do currículo se confunde com a história da educação e consequentemente com a história das teorias pedagógicas. Segundo Saviani (1998), seu emprego na educação surge com o objetivo de sequenciar, disciplinar e ordenar o percurso escolar. A origem do currículo remonta a reforma protestante no final do século XVI, nos países de língua inglesa. Nesse período, "[...] a ideia de currículo fazse logo acompanhar pelas de ordem (no sentido se sequência interna) e de disciplina (no sentido de coerência estrutural) como elementos indispensáveis a qualquer curso" (SAVIANI, 1998, p. 20).

Remetemo-nos a história do currículo. Contudo, nesse texto, o compreendemos para além de um conceito abstrato, e sim a partir das práticas realizadas dentro da escola. Em vista disso, o currículo tem um papel na práxis educativa de selecionar, organizar e socializar os conhecimentos historicamente adquiridos de acordo com as finalidades da educação. O currículo, enquanto práxis poderá ser efetivado no processo de reflexão da ação, no qual os docentes atuam no movimento teórico-prático construído no cotidiano das escolas. 
Nessa perspectiva, o currículo antes de ser um modelo, uma matriz, uma forma de conduzir as aprendizagens na escola, ele é práxis que não termina com 0 projeto de cultura socializado nas escolas, ele é prática que se manifesta através da função da escola de socialização/transmissão da cultura produzida historicamente, que vai se estruturando a partir de diversas práticas, entre elas a prática pedagógica (ensino), que é desenvolvida nas instituições de ensino (SACRISTÁN, 1998). O Currículo apresenta uma relação direta entre a teoria e a prática (práxis), "[...] como projeto baseado num plano construído e ordenado, relaciona a conexão entre determinados princípios e uma realização dos mesmos, algo que se há de comprovar e que nessa expressão prática concretiza seu valor" (SACRISTÁN, 1998, p. 16).

O currículo integrado ${ }^{1}$ prevê a formação a partir do trabalho, da ciência, da cultura e da tecnologia. Essa organização curricular vai além da interdisciplinaridade, pois tem como pressupostos: a compreensão do sujeito como ser histórico-social concreto; tem a formação humana como objeto central das áreas de conhecimentos; concebe 0 trabalho como princípio educativo; considera a coesão entre conhecimentos gerais e específicos; e é baseado numa pedagogia que considere a elaboração colaborativa entre as áreas de conhecimentos e que tenha como centro os embasamentos das diferentes técnicas que constituem o trabalho moderno (RAMOS, 2012). Assim, o currículo integrado pode:

[...]possibilitar às pessoas compreenderem a realidade para além de sua aparência fenomênica. Sob essa perspectiva, os conteúdos de ensino não têm fins em si mesmos nem se limitam a insumos para o desenvolvimento de competências. Os conteúdos de ensino são conceitos e teorias que constituem síntese da apropriação histórica da realidade material e social pelo homem (RAMOS, 2012, p. 115).

Para Ramos (2012), três princípios filosóficos norteiam a organização de um currículo integrado:

O primeiro destaca o sujeito como ser histórico-social, ou seja, é necessário que o indivíduo atue sobre a natureza, transformando-a para satisfazer suas necessidades (trabalho), de tal modo que nesse processo ele adquire conhecimento. "Assim, a história da humanidade é a história da produção da existência humana, e a história do conhecimento é a história do processo de apropriação social dos potenciais da natureza para o próprio homem, mediada pelo trabalho" (RAMOS, 2012, p. 115).

O segundo enfatiza que a realidade concreta deve ser compreendida em sua totalidade, nesse sentido "totalidade significa um todo estruturado e dialético, do qual

\footnotetext{
${ }^{1}$ Destacamos que a discussão sobre o currículo integrado aponta outros estudos como o de Santomé (1998) e Bernstein (1996). Entretanto, nessa pesquisa, abordaremos o currículo integrado a partir de autores que discutem seus fundamentos com base na concepção de ensino médio integrado à educação profissional.
} 
um fato ou conjunto de fatos pode ser racionalmente compreendido pela determinação das relações que o constituem" (RAMOS, 2012, p. 115).

O terceiro é epistemológico, pressupõe entender que o conhecimento é abstraído da realidade concreta.

Isto posto, o currículo integrado "organiza o conhecimento e desenvolve o processo de ensino-aprendizagem de forma que os conceitos sejam apreendidos como sistema de relações de uma totalidade concreta que se pretenda explicar/compreender" (RAMOS, 2012, p. 115). Entretanto, compreendemos que não é extinguindo o currículo organizado por disciplinas, e adotando um currículo estruturado por áreas de conhecimento ou projetos que será solucionado o problema da fragmentação do conhecimento. Só será possível a implementação do currículo integrado entendendo os princípios filosóficos que o norteiam. Como evidencia Ciavatta (2012, p. 94):

A lógica multidisciplinar, sobre a qual, historicamente, se baseou o currículo escolar, foi condenada como uma lógica de fragmentação do saber. Definiu-se a renovação metodológica tendo por base as competências a serem desenvolvidas pelos alunos. $E$ as disciplinas deveriam ser eliminadas do currículo para dar lugar a aprendizagens por projetos, por problemas etc. No entanto, o conhecimento e 0 ato de conhecer se fazem mediante a compreensão dos conceitos científicos que são organizados na escola na forma de conteúdos de ensino. A compreensão dos fundamentos que explicam os processos naturais e sociais, o desenvolvimento tecnológico, e a produção moderna, possibilitando a aprendizagem significativa e a construção de novos conhecimentos, exige que os conceitos científicos sejam aprendidos nas suas raízes epistemológicas. De onde se conclui que a eliminação das disciplinas anula a especificidade das ciências e compromete a aquisição de conhecimentos como um todo.

Dessa forma, numa concepção dialética a integração se dá na construção da totalidade através das partes (disciplinas, áreas de conhecimentos, entre outros). Nesse contexto, não é o formato de organização do ensino médio que o coloca na condição de integrado. Mas exige-se que busquem-se os fundamentos da produção da existência, objetivando a formação humana na sua essência.

Ramos (2012, p. 123-124) propõe o seguinte desenho para elaboração de um currículo integrado:

a) Problematizar fenômenos - elaborar questões e propor problemas em que os estudantes precisem recorrer à teoria para poder solucionar os desafios impostos pela prática;

b) Explicitar teorias e conceitos fundamentais para a compreensão dos objetos estudados nas múltiplas perspectivas - o entendimento dos fenômenos a partir de diferentes áreas da ciência;

c) Sistematizar os conceitos como conhecimentos de formação geral e específica com base nos conhecimentos produzidos historicamente (científicos, culturais, filosóficos, entre outros); 
d) Organizar os componentes curriculares e as práticas pedagógicas - objetivando elaborar os conhecimentos fundamentados na totalidade dos conceitos.

Para que o currículo integrado se construa de fato na prática pedagógica, é preciso que ele seja elaborado com base em um processo democrático a partir de um movimento de reflexão sobre os sujeitos que queremos formar. Os docentes precisam ser os atores principais, neste movimento de discussão, para que o currículo construído se efetive no cotidiano da escola.

\section{PERCURSO METODOLÓGICO DA PESQUISA}

Nessa pesquisa, fizemos a opção pelo método dialético e a abordagem qualitativa. Visto que pesquisamos a realidade em sua totalidade, levando em consideração o contexto histórico, político, econômico, entre outros.

$\mathrm{Na}$ fase exploratória, a coleta de informação se deu por meio da pesquisa bibliográfica e documental, possuindo como objetivo o contato com o arcabouço teórico já elaborado.

Realizamos a análise documental devido à necessidade de pesquisar os documentos e Leis que norteiam o funcionamento da instituição investigada: Projeto Pedagógico do Curso, Projeto Político Pedagógico da Instituição, Plano de Desenvolvimento Institucional, Diretrizes do Ensino Médio, Diretrizes da Educação Profissional Técnica de Nível Médio, entre outros.

Nessa investigação, recorreremos às seguintes fontes: revistas, livros, artigos e teses. Os principais autores escolhidos para mediar essa discussão foram: Ramos (2012, 2014 e 2017), Ciavatta (2012, 2014), Gramsci (1982), Saviani (2011), Duarte Neto (2013), Sacristán (1998), dentre outros.

O campo de pesquisa escolhido foi o Curso Técnico em Agropecuária do Ifal - Campus Santana do Ipanema. Amparamo-nos em Minayo (2009), que compreende por campo, na pesquisa qualitativa, um recorte que o pesquisador faz em termo de espaço, o qual retrata a realidade empírica a ser pesquisada a partir das perspectivas teóricas que fundamentam o objeto investigado.

Os participantes da pesquisa foram os docentes (Licenciados e Bacharéis) do Curso Técnico em Agropecuária do Instituto Federal de Educação, Ciência e Tecnologia de Alagoas - Campus Santana do Ipanema - que possuem no mínimo um ano de atuação no curso.

A coleta de informações com os sujeitos da pesquisa foi realizada por meio de dois procedimentos: a entrevista semiestruturada e o grupo focal (GF). Primeiro, fizemos uma pesquisa exploratória com os docentes a partir das entrevistas e depois realizamos uma sessão de GF com o objetivo de compreender as práticas curriculares.

A análise e a interpretação das informações foram realizada a partir da análise de conteúdo temática. Após o processo de organização e transcrição de todo o corpus documental a ser analisado, elaboramos a categorização fundamentada em dados abertos (ESTEVES, 2006). Para tanto, tivemos como categorias iniciais: ensino médio integrado, currículo integrado e prática pedagógica, que foram objetos centrais nesse 
estudo, elas foram somadas aos indicadores que surgiram da análise das falas dos docentes.

$\mathrm{Na}$ análise, as categorias e os indicadores foram combinados com o objetivo de aprofundar as discussões sobre a temática à luz dos pressupostos teóricos. Nessa perspectiva, tivemos atenção ao expor as vivências dos docentes, traduzindo as práticas de modo a produzir contribuições com bases científicas.

\section{A PRÁTICA PEDAGÓGICA DOS DOCENTES DO CURSO TÉCNICO INTEGRADO EM AGROPECUÁRIA - ANÁLISE E DISCUSSÃO DOS RESULTADOS}

Nesta seção, analisaremos as informações coletadas através das entrevistas semiestruturadas, do grupo focal e dos documentos institucionais.

Realizamos análise de conteúdo temática partindo das categorias Ensino Médio Integrado, Integração Curricular e Prática Pedagógica. A seguir detalharemos cada uma dessas categorias.

\subsection{ENSINO MÉDIO INTEGRADO}

Abordaremos a compreensão que os docentes têm da proposta do EMI, fundamentada pelos pressupostos teóricos.

Os docentes, em sua maioria, têm uma compreensão do EMI com base nas orientações propostas pelas Diretrizes Curriculares Nacionais da Educação Profissional Técnica de Nível Médio², no sentido de pensar no currículo articulando educação básica e profissional.

O Art. 7ํㅡ, alínea a, das Diretrizes Curriculares Nacionais da Educação Profissional Técnica de Nível Médio diz que o EMI deve ser ofertado "somente a quem já tenha concluído o ensino fundamental, com matrícula única na mesma instituição, de modo a conduzir o estudante à habilitação profissional técnica de nível médio ao mesmo tempo em que conclui a última etapa da Educação Básica" (BRASIL, 2012). Desta maneira, também compreende o Docente $3^{3}$ (2019) "um modelo bem-sucedido, [...] o instituto federal tem uma tecnologia pronta, porque ele tenta associar uma necessidade de formação e profissionalização que o nosso público tem".

Pensando educação básica e formação profissional, nos moldes do Ifal, visa uma formação para o mercado de trabalho e para a vida. No instituto federal, pelo menos do ponto de vista legal, temos a missão

\footnotetext{
2 Resolução № 6, de 20 de setembro de 2012.

3 Em virtude do direito à privacidade dos participantes da pesquisa, a identidade deles (nomes e sobrenomes) não será divulgada. Utilizaremos o termo Docente, seguido de um número que irá diferenciar os participantes e do ano em que foi realizada a coleta das informações.
} 
de ir além da formação técnica, com disciplinas e conteúdos que fazem ele refletir sobre a posição dele como cidadão, como um ser mais holístico que não visa somente o trabalho, um ser que se relaciona com outras pessoas, que é cidadão. Pode ter outras competências que não tem muito a ver com o mercado de trabalho, como, por exemplo, as artes e o esporte (DOCENTE 9, 2019, grifo nosso).

O docente citado evidencia que sua compreensão advém do ponto de vista legal, que nos faz refletir sobre a necessidade de aproximação do que está na Lei com a prática pedagógica e com os pressupostos epistemológicos e filosóficos, contribuindo, deste modo, para a formação de sujeitos que possam ser protagonistas de seus destinos.

Para o Docente 5 (2019), "a integração curricular, significa somar o conhecimento, ou seja, transcende a questão do aluno sair daqui somente para o mercado de trabalho. Mas, também, com um desenvolvimento pessoal". O Docente 8 (2019) tem a seguinte compreensão:

Vejo o currículo integrado como uma grande vantagem [...] de propiciar ao aluno uma visão mais social da realidade. Você trabalha diversos conceitos a partir de vários pontos de vista: do ponto de vista da física, do ponto de vista da matemática. Proporcionando ao aluno, diversas maneiras de enxergar a realidade.

Para além da articulação entre educação básica e profissional, eles destacam a importância da formação omnilateral. A formação omnilateral é uma concepção de educação humana que se constitui com base nas condições objetivas e subjetivas, para o desenvolvimento histórico do estudante. Ou seja, é a formação que envolve as dimensões material e não material do ser humano: intelectual, cultural, afetivo, psicossocial, estético e lúdico. Desse modo, envolve todos os sentidos humanos que podemos construir socialmente (FRIGOTTO, 2012). De acordo com o que relata o Docente 11(2019):

Eu percebo que o currículo integrado no instituto é uma tentativa institucional de tornar possível essa formação que articula a questão da teoria, da prática e do trabalho como princípio educativo. Essa busca sempre de articular as atividades que são feitas no contexto escolar no sentido de não ter esse aluno como mera mão de obra que não exerce a reflexão, não tenha condições de produzir conhecimento, ao contrário uma formação mais ampla. É nesse sentido que eu faço a leitura.

Em suas falas, os docentes também enfatizam o caráter interdisciplinar que é assegurado à proposta do EMI, que tem como objetivo superar a fragmentação do conhecimento, promovendo um diálogo entre as diversas áreas de conhecimento. Como destaca o Docente 4 (2019) "é a interação com professores de diversas áreas, tanto da base comum quanto da base técnica". Entretanto, concebemos que a 
interdisciplinaridade é uma possibilidade e não o fim na proposta do EMI, ou melhor, ela pode ser considerada uma metodologia de trabalho.

Sendo assim, é preciso estar atento para que a interdisciplinaridade não assuma o lugar de justaposição de disciplinas, mas que ela possa ser instrumento na construção da totalidade dos conhecimentos e no processo de transmissão/ socialização dos saberes escolares.

Por fim, resumimos, em linhas gerais, como os docentes concebem o EMI: Interação entre os docentes das diversas áreas; Um diálogo interdisciplinar; Ir além da formação técnica, com as disciplinas e os conteúdos que fazem com que o estudante reflita sobre a posição dele como cidadão; Formação para o mundo do trabalho; e Desenvolvimento omnilateral do estudante.

\subsection{INTEGRAÇÃO CURRICULAR}

Nesta seção, discutiremos como a integração curricular se expressa no projeto pedagógico do curso e as dificuldades para execução da proposta.

Em vista disso, compreendemos o currículo integrado alicerçado na concepção de educação politécnica e omnilateral; tendo o trabalho como princípio educativo e integrando conhecimentos gerais e específicos como totalidade na proposta curricular, em que a finalidade da educação é a formação humana que promova à classe trabalhadora a elaboração de conhecimentos que apontem para um horizonte de transformação social.

Ao analisarmos o texto do Projeto Pedagógico do Curso Técnico Integrado em Agropecuária (PPC) encontramos elementos que remetem à formação humana dos estudantes, tendo o "[...] trabalho como princípio educativo, a educação como estratégia de inclusão social, a gestão democrática e participativa e a indissociabilidade entre ensino, pesquisa e extensão" (IFAL, 2015, p. 6).

A Organização curricular é composta por três núcleos: básico, integrado e profissional. Segundo o PPC, "trata-se de uma concepção curricular que defende o desenvolvimento de práticas pedagógicas integradoras [...] à medida que as disciplinas se constituem do agrupamento dos fundamentos do Ensino Médio Propedêutico e da Formação Profissional" (IFAL, 2015, p. 14). Apesar do diálogo constante sobre integração em vários momentos do projeto, a matriz curricular e os planos de ensino não expressam de forma clara como se dará a integração dos conhecimentos.

Como foi apresentado, existe no PPC os pressupostos legais e epistemológicos que a proposta do EMI requer. Entretanto, falta o caminho, ou melhor, o percurso metodológico. De acordo com o Docente 11 (2019), "o nosso projeto pedagógico, ele explicita essa intenção institucional de ter uma articulação entre os componentes curriculares, apesar de não nortear o como fazer isso".

Os docentes ressaltam, em vários momentos dos nossos diálogos, que existe um distanciamento entre o que está escrito no PPC e as práticas que são realizadas no curso. Assim, destaca o Docente 8 (2019) "eu tive oportunidade de ler o PPC, ele propõe, em vários trechos, ele relata alguns pontos que deveriam ser mais rigorosamente seguidos, mas que na prática, infelizmente, não acontece”. 
A prática pedagógica deve ser elaborada através da relação teoria e prática. Por isso é necessário que se faça um aprofundamento teórico sobre a proposta de educação que se propõe realizar, para que as práticas elaboradas possam ser sólidas. Como bem explica Saviani (2007, p. 107), "[...] tanto a teoria como a prática são importantes no processo pedagógico, do mesmo modo que esse processo se dá na relação professor-aluno não sendo, pois, possível excluir um dos polos da relação em benefício do outro".

Os docentes apontaram algumas dificuldades na execução da proposta de ensino médio integrado, são elas: organização do tempo pedagógico, falta de formação para trabalhar com o currículo integrado e ausências de estratégias e programas institucionais para o desenvolvimento do EMI. A seguir abordaremos essas dificuldades.

\subsubsection{Organização do tempo pedagógico}

Um dos problemas destacados pelos docentes é o tempo pedagógico, ou melhor, eles apontam que o tempo é muito curto para todas as rotinas da prática pedagógica. Visto que, planejar e ministrar aulas; corrigir avaliações; fazer pesquisa e extensão; e atender os alunos individualmente, toma muito tempo.

Contudo, reconhecem a necessidade de tempo para planejar as atividades integradoras e dialogar sobre o fazer pedagógico no EMI. Conforme destaca o Docente 2 (2019), "Precisamos reavaliar como um todo, para que tenhamos tempo. Pois esse processo de educação vai além da questão de sala de aula, preparação de prova, preparação de aula, entre outros".

Ressaltam que existem poucos momentos de discussão sobre 0 desenvolvimento do ensino médio integrado. De acordo com o Docente 10 (2019), "tem muita reunião burocrática e pouca pedagógica. Semana pedagógica é só para falar o que deve ser feito e o que não deve, mas não tem um momento para integrar, conversar, pegar as ementas e comparar como é".

Outro ponto, que foi bastante evidenciado, é a necessidade de diálogo entre os docentes como um aspecto fundamental, a fim de que possam de fato fazer a integração curricular. Essa integração se faz no diálogo coletivo. Dessa forma, precisamos que estejam abertos a inovação para que possam trabalhar as disciplinas e os projetos de forma integrada, proporcionando aos estudantes "[...] horizontes de captação do mundo além das rotinas escolares, dos limites do estabelecido e do normatizado, para que ele se aproprie da teoria e da prática que tornam o trabalho uma atividade criadora, fundamental ao ser humano" (CIAVATTA, 2012, p. 101).

Percebemos que existe uma necessidade latente de que a instituição disponibilize tempo e espaço para o planejamento coletivo. Para Ramos (2014, p. 96), "a geração de tempos e espaços docente para a realização de atividades coletivas é preceito inegociável quando se tem essa finalidade", a finalidade de um currículo integrado.

5.2.2 Falta de formação para trabalhar com o currículo integrado 
A ausência de formação específica para trabalhar com a educação profissional e tecnológica e com o currículo integrado é outra dificuldade enfatizada pelos docentes. Entendemos que essa dificuldade não ocorre somente no Ifal, mas também em todo Brasil. Pois faltam políticas educacionais específicas para esta formação. A fala da Docente 5 (2019) deixa clara essa necessidade:

Veja, é uma dificuldade muito grande, eu repenso isso constantemente, como fazer essa integração? Como integrar esses conteúdos? Disciplinas básicas da formação geral com as disciplinas técnicas? Acho que isso é um impasse para todo mundo, não me sinto preparada. Gostaria realmente de uma formação prática, atuante.

Os docentes compreendem a necessidade de construção do diálogo com a instituição, no sentido de formar os servidores para atuar no EMI. "Reconheço que a maioria dos professores ainda não estão preparados para fazer essa integração. 0 próprio fato de eles terem sido forjados com uma visão diferente. Sinto um certo receio de buscar essa integração, cada um se fecha no seu 'quadrado'” (DOCENTE 8, 2019).

Reconhecem, inclusive, que as licenciaturas pouco contemplam as discussões específicas sobre a EPT e o EMI. Existe uma necessidade de formação de professores para atuar na educação profissional tecnológica. Para Moura (2008), esta formação pode ser planejada a partir de duas possibilidades: cursos de licenciatura voltados para a educação profissional e a pós-graduação lato e stricto sensu.

Compreendemos que os docentes são sujeitos que produzem e mobilizam diversos saberes em sua prática pedagógica, refletindo sobre os conteúdos e as formas de ensinar. Sendo assim, é mister que eles tenham clareza dos objetivos e finalidades do EMI para não cair nos modismos educacionais.

Para além da formação inicial e da pós-graduação, é preciso que a instituição planeje a formação continuada em serviço dos docentes. Essas formações podem ocorrer em eventos semestrais para toda comunidade acadêmica. Mas, principalmente, devem ser construídos grupos de estudos permanentes sobre as bases epistemológicas e filosóficas do EMI. Esses grupos necessitam agregar gestores, pedagogos, técnicos em assuntos educacionais e docentes responsáveis pela formação geral e pela formação profissional. Deste modo, podemos construir uma prática pedagógica tendo como objetivo a formação dos indivíduos para a superação e transformação social.

5.2.3 Ausências de estratégias e programas institucionais para o desenvolvimento do EMI

Além da necessidade de formação, os docentes relatam que sentem falta de estratégias institucionais que mobilizem a constante discussão da prática curricular do EMI, em que eles possam ser incentivados a conversar, socializar e integrar as ações e projetos desenvolvidos. 
Nós percebemos que há de fato, em alguns momentos, uma tentativa de integração, entretanto, essa integração vem muito mais no micro, como uma decisão individual, com um colega que partilha um momento na sala de aula ou na sala dos professores. Tanto é que vamos percebendo que as situações de articulação acontecem com as pessoas que dão aula no mesmo dia, não vejo isso ser promovido no âmbito institucional. Não vejo do ponto de vista institucional, certas estratégias e certas rotinas que nos façam de fato fazer com que essas ações pontuais e micro, passem a ser da instituição e não dependa da minha decisão de fazer (DOCENTE 11, 2019).

Observamos que a instituição propõe o EMI, contudo, não apresenta ações que provoquem e mobilizem uma prática pedagógica integrada. Como destaca o Docente 11 (2019) "enquanto nós não tivermos uma flexibilidade de aceitar o outro na nossa prática pedagógica, mas, também, enquanto a estrutura não permitir que essa prática seja integrada, podemos discutir, porém não vai sair do livro".

Tratam também das dificuldades estruturais: ausências de laboratórios; espaço para práticas esportivas e artísticas; bem como do número alto de alunos por turma; e o excesso de carga horária, o que dificulta o desenvolvimento da pesquisa e extensão.

Apesar de reconhecerem as dificuldades no desenvolvimento da proposta do EMI, os docentes afirmam o quanto a formação integrada promove um diferencial na vida dos estudantes:

A proposta ela é interessantíssima, é de ficar encantada realmente, integrar esse ensino médio com o técnico, é o que observamos aqui com os nossos. O quanto que eles são transformados, aos pouquinhos observamos, [...] existe uma mudança regional, no desenvolvimento pessoal desses meninos, é brilhante. Agora, estamos longe da educação integrada ideal, temos que trabalhar muito para chegar (DOCENTE 5, 2019).

Apesar das dificuldades encontradas para implantação do EMI, sejam elas pedagógicas, estruturais ou financeiras. Não podemos esperar as condições ideais para construir um projeto de educação integrada. "Acreditamos que condições podem e devem ser garantidas. Mas não é possível aguardar as condições ideais para dar início a um projeto de tamanha relevância. A própria definição e conquista de tais condições é uma tarefa coletiva" (RAMOS, 2014, p. 100).

\subsection{PRÁTICA PEDAGÓGICA}

Apresentamos de que forma se expressam as práticas integradoras realizadas pelos docentes. No entanto, compreendemos que o ensino integrado, para além de práticas realizadas, precisa ser entendido na sua essência, enquanto uma concepção de ensino. De acordo com o que propõe Araújo e Frigotto (2015, p. 62): 
Não apenas uma forma de oferta da educação profissional de nível médio, o ensino integrado é uma proposição pedagógica que se compromete com a utopia de uma formação inteira, que não se satisfaz com a socialização de fragmentos da cultura sistematizada e que compreende como direito de todos ao acesso a um processo formativo, inclusive escolar, que promova o desenvolvimento de suas amplas faculdades físicas e intelectuais.

É importante destacar que temos clareza de que as práticas apresentadas não são rotineiras, fazem parte de momentos pontuais na instituição. Os docentes ressaltam que sentem resistência por parte de alguns, quando são convidados a planejarem atividades integradoras. Isso dificulta a execução da proposta, pois as estratégias acadêmico-científicas de integração precisam ser elaboradas e discutidas coletivamente.

Umas das atividades integradoras são desenvolvidas nos sábados letivos. Elas são planejadas por área do conhecimento, em que cada área desenvolve atividades variadas, como: dia de campo, visita técnica, aula prática, palestra, oficina, sessão de cinema, entre outras. Essas atividades ocorrem relacionando os componentes curriculares de cada área e utilizando abordagens que podem contribuir para integração dos conteúdos, relacionando teoria e prática. Inclusive, por vezes, elas são realizadas no ambiente extraescolar, tais como: fazendas, áreas de preservação permanente, museus, parques arqueológicos, empresas, entre outros.

As práticas integradoras aqui referenciadas contemplam, em certa medida, a dimensão metodológica do ensino médio integrado. No entanto, essas práticas não ocorrem de forma sistemática. Percebemos que a instituição não concebeu a formação integrada na sua dimensão epistemológica, política e filosófica.

Nesse sentido, é importante refletir a formação humana, em que os estudantes compreendam a realidade e possam, também, atuar como profissionais. Esse trabalho precisa ser assumido enquanto um projeto da instituição de ensino junto com os servidores, de modo que sejam planejadas coletivamente todas as ações que serão desenvolvidas.

Por fim, não conseguimos atingir esses aspectos no âmbito do curso objeto desse estudo. Os docentes compreendem a dimensão da proposta do EMI, todavia é necessário construir um espaço institucional de aproximação com o ensino médio integrado.

\section{CONSIDERAÇÕES FINAIS}

A elaboração do projeto do EMI precisa ser coletivo, com base no planejamento participativo e democrático. Para isso, é fundamental ter clareza da concepção de educação, da metodologia e dos objetivos de ensino. A prática da formação integrada deve ser uma experiência de democracia participativa, sem autoritarismo, assim, constituindo uma opção coletiva (CIAVATTA, 2012). 
No diálogo com os docentes sobre a concepção de ensino médio integrado e a prática do currículo integrado. Eles foram apresentando a compreensão que têm da proposta, bem como as angústias por acreditarem que não conseguem sistematizá-lo na prática.

Nesse cenário, concluímos que a prática pedagógica dos docentes voltada à sistematização do EMI ainda é muito incipiente. Existe, por parte dos participantes da pesquisa, o desejo de desenvolver práticas integradoras, porém é fundamental que a instituição de ensino mobilize ações nessa perspectiva. Ademais, observamos que a instituição propõe o EMI nos seus documentos institucionais. Apesar de não apresentar ações sistêmicas que promovam uma prática pedagógica integrada.

Para a efetivação do EMI, é fundamental que a concepção esteja bem sistematizada no projeto pedagógico do curso: referenciada nos objetivos e nas metodologias; e propondo as práticas, os espaços de discussão, o planejamento coletivo e a avaliação das ações. E, principalmente, que seja elaborada coletivamente a partir dos pressupostos epistemológicos, políticos e filosóficos que orientam essa concepção.

Em suma, a prática pedagógica no EMI em que acreditamos, fundamentada na formação politécnica e omnilateral, ainda está no horizonte. A fim de colocá-la em prática, é necessário que continuemos com o propósito de construir um ensino médio integrado, que contribua para superação da dualidade entre formação geral e formação profissional, com base na articulação entre o trabalho, a ciência, a cultura e a tecnologia orientando a emancipação humana dos sujeitos.

\section{REFERÊNCIAS}

ARAÚJO, R. M. d. L.; FRIGOTTO, G. Práticas pedagógicas e ensino integrado. Revista educação em questão, Natal, v. 52, n. 38, p. 61-80, maio/ago. 2015.

BERNSTEIN, B. A estruturação do discurso pedagógico: classe, código e controle. Petrópolis: Vozes, 1996.

BRASIL. Lei de diretrizes e bases da educação № 9.394/1996, de 20 de dezembro de 1996. Disponível em: http://www.planalto.gov.br/ccivil_03/leis/L9394.htm. Acesso em: 26 jan. 2019.

BRASIL. Resolução № 6, de 20 de setembro de 2012. Diretrizes Curriculares Nacionais para a Educação Profissional Técnica de Nível Médio. Disponível em: $<$ http://portal.mec.gov.br/index.php?option=com_docman\&view=download\&alias=11 663- rceb006-12-pd. Disponível em: Acesso em: 26 nov. de 2019.

CIAVATTA, M. A formação integrada: a escola e o trabalho como lugares de memória e de identidade. In: FRIGOTTO, G.; CIAVATTA, M.; RAMOS, M. (Org.). Ensino médio integrado: concepções e contradições. 3. ed. São Paulo: Cortez, 2012.

CIAVATTA, M. Ensino integrado, a politecnia e a educação omnilateral: Por que lutamos? Revista Trabalho \& Educação, v. 23, n. 1, p. 187-205, 2014. Disponível em: Acesso em: 26 nov. de 2019. 
CIAVATTA, M. A; RAMOS, M. N. Ensino médio e educação profissional no Brasil: dualidade e fragmentação. Revista retratos da escola, Brasília, v. 5, n. 8, p. 27-41, jan./jun. 2011. Disponível em:

http://retratosdaescola.emnuvens.com.br/rde/article/viewFile/45/42. Acesso em: 26 nov. 2019.

DUARTE NETO, J. H. A Epistemologia da prática: implicações para a formação de professores da educação básica. São Paulo: Paco, 2013.

ESTEVES, M. Análise de conteúdo. In: LIMA, J. A.; PACHECO, J. A. (Orgs.). Fazer investigação: contributos para a elaboração de dissertações e teses. Porto: Porto Editora, 2006.

FRIGOTTO, G. Educação Omnilateral. Dicionário da educação do campo. Rio de Janeiro, São Paulo: Escola Politécnica de Saúde Joaquim Venâncio, Expressão Popular, 2012.

GRAMSCI, A. A organização da escola e da cultura. Botafogo: Civilização Brasileira, 1982. Disponível em:

https://cesarmangolin.files.wordpress.com/2010/02/gramsci-os-intelectuais-e-aorganizacao-da-cultura1.pdf. Acesso em: 30 set. de 2019.

IFAL. Projeto pedagógico do curso técnico de nível médio integrado em agropecuária. 2015. Disponível em:

https://www2.ifal.edu.br/campus/site/campus_santana/ensino/educacao-basica. Acesso em: 02 de jan. de 2020.

MINAYO, M. C. Trabalho de campo: contexto de observação, interação e descoberta. In: MINAYO, M. C. de S. (org.) Pesquisa social: teoria, método e criatividade. 18. ed. Petrópolis: Vozes, 2009.

MOURA, D. H. Educação básica e educação profissional e tecnológica: dualidade histórica e perspectiva de integração. Revista holos, Natal, v.2, p. 1-27, 2007. Disponível em: http://www2.ifrn.edu.br/ojs/index.php/HOLOS/article/viewFile/11/110. Acesso em: 26 ago. 2019.

MOURA, D. H. A Formação de Docentes para a Educação Profissional e Tecnológica. Revista Brasileira da educação profissional e tecnológica, v. 1, n. 1, 2008. Disponível em:

http://www2.ifrn.edu.br/ojs/index.php/RBEPT/article/view/2863. Acesso em: 10 nov. de 2019.

RAMOS, M. N. Possibilidades e desafios na organização do currículo integrado. In: Ensino médio integrado: concepções e contradições. 3. ed. São Paulo: Cortez, 2012.

RAMOS, M. N. História e política da educação profissional [recurso eletrônico] / Marise Nogueira Ramos. - Dados eletrônicos (1 arquivo: 585 kilobytes). - Curitiba: Instituto Federal do Paraná, 2014. - (Coleção formação pedagógica; v.

5). Disponível em: http://curitiba.ifpr.edu.br/wpcontent/uploads/2016/05/Hist\%C3\%B3ria-e-pol\%C3\%ADtica-daeduca\%C3\%A7\%C3\%A3o-profissional.pdf. Acesso em: 26 nov. 2019.

RAMOS, M. N. Concepção do ensino médio integrado. In: Encontro Intercampi de Educação Profissional-EIEP, 1, 2017, Rio de Janeiro. Anais. Rio de Janeiro: CEFET, 2017. Disponível em: 
https://tecnicadmiwj.files.wordpress.com/2008/09/texto-concepcao-do-ensino-mediointegrado-marise-ramos1.pdf. Acesso em: 20 fev. 2019.

SACRISTAN, J. G. O currículo: uma reflexão sobre a prática. 3. ed. Porto Alegre: ARTMED, 1998.

SANTOMÉ, J. Globalização e interdisciplinaridade: o currículo integrado. Porto Alegre: Artes Médicas, 1998.

SAVIANI, D. Trabalho e educação: fundamentos ontológicos e históricos. Revista brasileira de educação. Campinas, v. 12, n. 32, p. 52-180, jan./abr. 2007.

Disponível em: http://www.scielo.br/pdf/rbedu/v12n34/a12v1234.pdf. Acesso em: 26 nov. 2019.

SAVIANI, D. Pedagogia histórico-crítica: primeiras aproximações. 11. ed. Campinas: Autores Associados, 2011.

SAVIANI, N. Saber escolar, currículo e didática: problemas da unidade conteúdo/método. 2. ed. Campinas: Autores Associados, 1998. 